\title{
The Asymmetric Impact of Funding Liquidity Risk on the Volatility of Stock Portfolios during the COVID-19 Crisis
}

\author{
Baris Kocaarslan ${ }^{1,2}$ and Ugur Soytas ${ }^{3, *(D)}$ \\ 1 Department of Business Administration, Middle East Technical University, 06800 Ankara, Turkey; \\ bariskocaarslan@gmail.com \\ 2 Department of Business Administration, Yalova University, 77200 Yalova, Turkey \\ 3 Department of Technology, Management and Economics, Sustainability Division, Technical University of \\ Denmark, Kgs. Lyngby, 2800 Lyngby-Taarbæk, Denmark \\ * Correspondence: uguso@dtu.dk
}

Citation: Kocaarslan, B.; Soytas, U. The Asymmetric Impact of Funding Liquidity Risk on the Volatility of Stock Portfolios during the COVID-19 Crisis. Sustainability 2021, 13, 2286. https://doi.org/10.3390/su13042286

Academic Editor: Darko Vukovic

Received: 26 December 2020

Accepted: 15 February 2021

Published: 20 February 2021

Publisher's Note: MDPI stays neutral with regard to jurisdictional claims in published maps and institutional affiliations.

Copyright: (c) 2021 by the authors. Licensee MDPI, Basel, Switzerland. This article is an open access article distributed under the terms and conditions of the Creative Commons Attribution (CC BY) license (https:/ / creativecommons.org/licenses/by/ $4.0 /)$.

\begin{abstract}
In this study, we identify economic transmission channels through which changes in funding liquidity conditions in interbank markets asymmetrically affect volatilities of stock portfolios during the COVID-19 crisis. For the purpose of this study, the quantile regression approach is utilized. Controlling for macroeconomic factors, we document that volatilities of high-risk portfolios increase more in response to a deterioration in funding liquidity conditions compared to less risky portfolios. More importantly, this increase intensifies in high-volatility periods of high-risk portfolios, which implies the impact is stronger during uncertain economic environments, such as the one caused by the COVID-19 outbreak.
\end{abstract}

Keywords: funding liquidity; volatility; asymmetric relationship; COVID-19; quantile regression

JEL Classification: E44; G10; G20

\section{Introduction}

The ongoing COVID-19 pandemic is still adversely affecting people's lives (e.g., lockdowns, stay-at-home orders, sealing off cities, and closing borders), as well as economic activities and, hence, business conditions all over the world. The IMF's (the International Monetary Fund's) April 2020 report predicted a global growth rate of $-3 \%$ in 2020, which is worse than that during the global financial crisis (2008-2009) (IMF, World Economic Outlook, April 2020.). Governments have taken several measures (e.g., monetary and fiscal stimulus programs) to mitigate the adverse effects of the pandemic on the economy and to maintain financial stability. As a result of the uncertain economic environment caused by the COVID-19 pandemic, it is inevitable to see enormous impacts of the pandemic on financial markets via its long-lasting and far-reaching effects on the overall economy [1].

Some recent studies investigated the impact of the COVID-19 pandemic on the real economy and stock market behavior. The COVID-19 outbreak led to a tremendous impact on the stock market volatility and, ultimately, the volatility levels reached critical levels shortly thereafter, exceeding those observed during both the 1987 and the 2008 crises [2]. Using wavelet coherence analysis, Choi [3] demonstrated a strong impact of economic uncertainty on sector volatility of the S\&P 500 index in the COVID-19 period. Albulescu [4] showed that the prolongation of the COVID-19 pandemic is a crucial factor affecting financial market volatility and making risk management difficult. Zhang et al. [5] pointed out that the great uncertainty caused by the COVID-19 outbreak led financial markets to become unpredictable and highly volatile via its adverse impacts on the real economy. The results of Mazur et al. [6] indicated the extreme volatility of loser stocks, which was negatively associated with stock returns in the COVID-19 outbreak. Engelhardt et al. [7] found lower stock market volatility for high-trust countries (in response to COVID-19 case 
announcements). In another interesting study, Engelhardt et al. [8] showed that declining stock market returns were strongly related to news attention and weakly related to rational expectation during the COVID-19 crash. Overall, the related studies did not uncover how a risk factor affects the volatility of high-risk and low-risk stock portfolios depending on volatility levels in uncertain times. To fill this information gap, the debt constraint of financial intermediaries is considered as a risk factor in this study because financial intermediaries are the biggest speculators in global markets $[9,10]$.

Uncertainty plays a crucial role in affecting hedging demands and market volatility, especially during economic recessions [11,12]. Financial intermediaries are important types of investors with the ability to quickly trade various asset classes [13]. Despite the serious theoretical arguments about the key role of financial intermediaries in asset markets in [9], to the extent of our knowledge, there is no empirical study investigating the asymmetric dependence structure between changes in the risk-bearing capacity of financial intermediaries and the volatilities of stock portfolios during uncertain times (e.g., the COVID-19 pandemic times). The changes in the funding liquidity conditions in interbank markets (especially in high-uncertainty periods) can be used as a proxy for the changes in the risk-bearing capacity of financial intermediaries according to the theoretical insights of Brunnermeier and Pedersen [9]. To model the relationships in financial markets in tough times (such as the COVID-19 pandemic crisis period characterized by nonlinear shifts) correctly, one needs to consider the structure of nonlinear dependence between the variables in the model [14]. Considering the economic transmission channels, the main purpose of this paper was to study the asymmetric dependence between funding liquidity conditions and the volatilities of stock portfolios (including low-risk and high-risk portfolios) during the COVID-19 pandemic crisis. We also controlled for monetary conditions, exchange rate dynamics, and business cycle fluctuations via additional variables (e.g., default spread, term spread, reserve currency (United States dollar (USD)), and federal funds rate).

This study is grounded on an economic mechanism through which financial intermediaries provide market liquidity and, hence, affect the volatility of assets in global markets. In our investigation, we take into consideration the availability of funding constraints faced by financial intermediaries, who act as speculators in stock markets, leading to lower market liquidity and, therefore, inducing higher risk premium, especially for high-risk assets. This role played by financial intermediaries is expected to be intensified during high-uncertainty periods (see more details about the theoretical arguments in [9]). Hence, we hypothesize that the volatility of a high-risk portfolio is more sensitive to funding conditions in interbank markets than that of a low-risk portfolio during the COVID-19 pandemic. We further hypothesize that this sensitivity is more pronounced during highvolatility periods of high-risk portfolios. The economic mechanism behind our hypotheses is discussed in detail in Section 2.

In sum, this paper examines how the dynamic relationship between the risk-bearing capacity of financial intermediaries and the volatilities of stock portfolios varies during the COVID-19 pandemic, controlling for business cycles, exchange rate dynamics, and monetary conditions. The quantile regression (QR) framework enabled us to observe whether this dynamic link depends on the volatility levels. Our baseline findings suggest that the volatilities of high-risk portfolios are more vulnerable to the deterioration of funding liquidity conditions compared to low-risk portfolios. This vulnerability is more pronounced during high-volatility periods. An increase in the funding liquidity risk intensifies portfolio volatilities (especially the volatilities of high-risk portfolios) during high economic uncertainty caused by the COVID-19 pandemic. Overall, our study shows that financial intermediaries play an important role in risky portfolio volatility spikes during the pandemic.

We contribute to the literature in three unique ways. First, we develop a scientific explanation of how the tightening funding constraints of financial intermediaries play a critical role in driving the volatility of stock portfolios during an uncertain period (the COVID-19 pandemic period). Second, we suggest that the funding liquidity risk should 
be regarded as a major risk factor influencing the volatility of stock portfolios depending on their volatility levels in an uncertain economic environment. Third, we emphasize the importance of the precautionary measures taken by financial intermediaries in tranquil periods to increase their resilience to negative shocks in global markets, such as the one caused by the COVID-19 outbreak. These measures are quite likely to enhance the financial stability of global markets in bad economic conditions.

\section{Hypothesis Development}

Various studies documented correlations between trading volume (a proxy for liquidity risk) and asset volatilities [15-17], whereas some others related market liquidity to asset prices [18-21]. Intuitively, one could argue that investors require risk premium induced by illiquid markets leading to lower prices in order to compensate for their inability (increased cost of trading) to trade quickly in these markets. The presence of illiquid stocks could strongly inflate portfolio-level volatility, especially for equally weighted portfolios [22].

The impact of funding liquidity on portfolio volatilities has not received any attention in the literature and, to the extent of our knowledge, has not been formally tested by considering asymmetric impacts in an uncertain economic environment. Financial intermediaries are active market players simultaneously impacting the volatility of many markets. They use both their own capital and their collateralized borrowing from other financiers to finance their trading activities [9]. Hence, the debt constraint of financial intermediaries is of central importance for their trading activities and, therefore, in influencing asset prices. Brunnermeier and Pedersen [9] established a link between funding liquidity and an asset's market liquidity in their model. According to their model, if market liquidity is sourced from funding liquidity, market volatility could be a direct proxy for fluctuations in market liquidity. They argued that the existence of funding constraints for financial intermediaries, who act as speculators in stock markets, leads to lower market liquidity and, consequently, induces higher market volatility. This process shows that market liquidity (and, hence, market volatility) is mainly driven by the speculators' funding constraints. The speculators' margins are related not only to the fundamental-based volatility but also to the liquiditybased volatility in the presence of uninformed financiers. Uninformed financiers could consider price volatility induced by market illiquidity as fundamental volatility, leading to higher margins [9].

A high level of uncertainty leads to limited market participation by investors [23]. In return, low market participation induces an increase in market volatility due to reduced market liquidity, which creates a need for hedging by market players. Mele [24] documented increased market volatility induced by fluctuating uncertainty in bad times. Financial intermediaries' capital and market uncertainty are interdependent factors simultaneously influencing the equity markets [9]. In an uncertain period (e.g., the COVID-19 pandemic period), tightening funding constraints of financial intermediaries, due to higher destabilizing margins, substantially decrease market liquidity [9]. Hence, market volatility driven by the worsening funding conditions, in an uncertain economic environment, increases more compared to tranquil periods. In light of the above information, we argue that negative shocks to funding liquidity are transmitted to the volatility of stock portfolios via reduced market liquidity. Furthermore, this transmission is stronger when there is increased uncertainty in the stock market (e.g., high economic uncertainty caused by the COVID-19 pandemic) during high-volatility periods. These economic mechanisms influence high-volatility assets more strongly than low-volatility ones because the difficulty of determining the fundamental value of high volatility (illiquid) assets increases the margin requirements caused by market illiquidity [9]. Taking the above arguments into consideration, the following testable hypotheses are suggested:

Hypothesis 1. The deterioration in funding conditions in interbank loan markets significantly increases the volatility of portfolios during the COVID-19 pandemic.

Hypothesis 2. This increase is stronger for the volatility of high-risk portfolios. 
Hypothesis 3. The impact of this increase is greatly amplified for the upward periods of high-risk portfolio volatilities.

\section{Data and Volatility Measures}

The sample period ranged from 2 January 2020 to 30 June 2020. Many researchers accept the date of 2 January 2020 as the beginning of the COVID-19 pandemic crisis (e.g., Goodell and Goutte [25]; Erdem [26]). Many studies considered the time-series property of the volatility of stock portfolios and employed the exponential generalized autoregressive conditional heteroskedastic (EGARCH) model [27] to measure the volatilities of assets. Using the EGARCH model, Fu [28] emphasized the importance of time-varying characteristics of the conditional volatility in predicting expected returns. Therefore, we first estimated the EGARCH model to obtain portfolio-level volatilities. The EGARCH $(1,1)$ model, which is one of the simplest and most robust specifications among volatility models, considers the asymmetric impact of positive and negative news and the time-varying behavior of portfolio volatilities [29].

We used standard sets of four portfolios (small-growth, small-value, large-growth, and large-value portfolios) sorted by market capitalizations (ME) and book-to-market ratios (B/M). Daily portfolio-level returns were used to estimate the volatilities of portfolios. We used both value-weighted and equally weighted portfolio returns. The equally weighted portfolios, which consist of relatively smaller and illiquid stocks, may be affected more by the bid-ask bounce problem, inflating volatility [22]. Portfolio returns were sourced from Kenneth French's online data library for the volatility estimations. Some studies, for example [28], used the Fama-French three factors [30] in the mean equation. We adopted the Carhart [31] four-factor model (including market, size, value, and momentum factors) to provide a better adjustment for risk in the mean equation of EGARCH specification, and we regressed daily excess returns of size-value portfolios on four factors. For robustness, we also used the Fama-French [32] five factors in the mean equation and obtained very similar results (We thank Kenneth French for kindly providing the data for the mean equation estimates; we do not report the results herein to save space; the results can be provided upon request). The estimated variance equation is represented as follows:

$$
\ln \left(h_{t}\right)=\beta_{0}+X\left|\frac{\varepsilon_{t-1}}{\sqrt{h_{t-1}}}\right|+\gamma \frac{\varepsilon_{t-1}}{\sqrt{h_{t-1}}}+\beta_{h} \ln \left(h_{t-1}\right),
$$

where $\beta_{h}$ and $X$ refer to GARCH and ARCH parameters, respectively, and $\gamma$ refers to the asymmetry parameter. The derived conditional variance is employed as a proxy for the volatility of stock portfolios, as commonly used in the relevant literature. For brevity, we do not report the variance equation coefficients. Some of our findings are worth mentioning. Compared to ARCH parameters, larger GARCH parameters indicate more significant impact of long-run volatility on the volatility of high-risk portfolios. Furthermore, not surprisingly, the sign of the asymmetry parameter $(\gamma)$ is negative, indicating significant leverage effects for high-risk portfolio volatilities. To put it in different words, negative shocks affect highly risky portfolio volatilities more than positive shocks compared to less risky portfolio volatilities due to low information quality. The results can be provided upon request.

The descriptive statistics of derived portfolio volatilities are presented in Table 1. VOLSGEP, VOLSGVP, VOLSVEP, VOLSVVP, VOLLGEP, VOLLGVP, VOLLVEP, and VOLLVVP represent the volatilities of small-growth equally weighted, small-growth valueweighted, small-value equally weighted, small-value value-weighted, large-growth equally weighted, large-growth value-weighted, large-value equally weighted, and large-value value-weighted portfolios, respectively. The portfolio volatilities exhibit leptokurtic behavior with extreme values in tails and are not normally distributed according to Jarque-Bera statistics. These characteristics indicate tail events in volatilities and, thus, support the use of the QR approach. 
Table 1. Descriptive statistics of derived portfolio volatilities.

\begin{tabular}{ccccccccc}
\hline & VOLSGEP & VOLSGVP & VOLSVEP & VOLSVVP & VOLLGEP & VOLLGVP & VOLLVEP & VOLLVVP \\
\hline Mean & 0.5134 & 0.2048 & 0.4677 & 0.0185 & 0.1181 & 0.0210 & 0.4823 & 0.1570 \\
Median & 0.2286 & 0.1553 & 0.3246 & 0.0115 & 0.0993 & 0.0187 & 0.1721 \\
Maximum & 3.2661 & 1.0006 & 4.9160 & 0.1672 & 0.6541 & 0.0725 & 9.0281 & 0.1128 \\
Minimum & 0.0734 & 0.0126 & 0.0888 & 0.0074 & 0.0061 & 0.0046 & 0.0195 & 0.0568 \\
SD & 0.6695 & 0.1864 & 0.5609 & 0.0201 & 0.0953 & 0.0120 & 1.1468 & 0.1467 \\
Skewness & 2.5116 & 1.6481 & 5.1217 & 4.8301 & 2.4763 & 1.8847 & 5.1393 & 3.4704 \\
Kurtosis & 8.8997 & 5.9565 & 36.4576 & 30.7382 & 12.1917 & 7.4606 & 32.9453 & 16.0921 \\
Jarque-Bera & 307.6971 & 100.4783 & 6274.7260 & 4421.4730 & 558.7030 & 174.7940 & 5137.1270 & 1125.3440 \\
Probability & 0.0000 & 0.0000 & 0.0000 & 0.0000 & 0.0000 & 0.0000 & 0.0000 & 0.0000 \\
\hline
\end{tabular}

Notes: Table 1 presents descriptive statistics of portfolio volatilities. VOLSGEP, VOLSGVP, VOLSVEP, VOLSVVP, VOLLGEP, VOLLGVP, VOLLVEP, and VOLLVVP represent the volatilities of small-growth equally weighted, small-growth value-weighted, small-value equally weighted, small-value value-weighted, large-growth equally weighted, large-growth value-weighted, large-value equally weighted, and large-value value-weighted portfolios, respectively.

As expected, the equally weighted portfolios are riskier than the value-weighted portfolios due to market microstructure problems, such as lower trading ability and, hence, the bid-ask bounce problem. This is because of larger weights allocated to smaller stocks in the equally weighted portfolios compared to the value-weighted portfolios. The risk of a portfolio increases with an increase in the weight of small companies in the portfolio due to imperfect information, higher business risk, and greater cost of capital, which make the volatility of equally weighted portfolios more cyclically sensitive. Furthermore, smallgrowth portfolios appear to be riskier than small-value portfolios. The main reason behind this result is that although small-growth firms have higher growth opportunities than their value peers and large firms, they are exposed to more volatile business environments due to some disadvantages, such as lack of know-how, funding deficiency, poor brand recognition, and uncertain long-run prospects. Furthermore, large-value portfolios are riskier than large-growth portfolios. It appears that large-value companies are more vulnerable to exogenous shocks during economic downturns than large-growth companies, which can be attributed to the higher cash-flow risk of large-value firms.

We use the TED spread (TED) to consider funding liquidity conditions in interbank markets. The TED spread (the difference between 3 month LIBOR (London Inter-Bank Offered Rate) based on US dollars and 3 month Treasury bill rates) is commonly used as a measure to take funding illiquidity into consideration. Higher values of the TED spread show a deterioration of funding liquidity conditions in interbank markets. The TED spread data were collected from the Federal Reserve Bank of St. Louis. Macroeconomic risk factors, i.e., default spread (DEF), term spread (TERM), exchange rates, and federal funds rate (FF) are important for asset returns and volatilities [33-36]. Therefore, we used DEF, TERM, FF, and USD (trade-weighted US dollar index) to control for business cycle fluctuations, exchange rate dynamics, and monetary conditions. While default spread (DEF) reflects changes in long-term business conditions, the term spread (TERM) has been shown to be a better proxy for explaining short-term business cycles [33]. During periods of weak economic conditions, default spread and term spread are expected to be high. Federal funds rate (FF) is considered to examine the impact of interest rates on the US economy since it is widely accepted as the most influential interest rate affecting financial and monetary conditions $[34,36]$ A significant US dollar appreciation is one of the important indicators of worsening economic conditions affecting volatilities in the stock markets in crisis periods with high uncertainty [35]. Daily data on the 10 year Treasury bond yields, 3 month Treasury bill, Moody's AAA-rated and BAA-rated corporate bond yields, trade-weighted US dollar index, and federal funds rate were sourced from the Federal Reserve Bank of St. Louis. The term spread refers to the difference between the yields on the 10 year Treasury bond and the 3 month Treasury bill. The default spread represents the difference between the yields on the BAA-rated and AAA-rated corporate bonds. Higher values of the trade-weighted US dollar index show a stronger US dollar in 
global markets. The percentage change of the trade-weighted US dollar index ( $\triangle \mathrm{USD}$ ) was used in the analysis.

\section{Quantile Regression Method}

To investigate the main determinants of the volatility of stock portfolios at varying volatility levels, we made use of the $\mathrm{QR}$ approach [37]. To model the relationships in global markets, some recent studies focused on asymmetric relationships between variables of interest using quantile regressions [38,39]. The QR model relaxes the standard assumptions of linear regression (e.g., homoscedasticity and normality assumptions). The use of the $\mathrm{QR}$ approach allows examining the funding liquidity risk-portfolio volatility relationship at different points of the volatility distribution. The $Q R$ approach provides a broader picture of how changes in funding liquidity conditions affect the behavior of portfolio volatilities depending on the level of the volatilities. See more detailed explanations about the quantile regression approach in Koenker and Hallock [40].

The QR function was modeled to investigate the effect of the conditional variables on the different quantiles of the dependent variable. The QR model is shown below. We benefited from the pair bootstrapping procedure proposed by Buchinsky [41] to derive the standard errors for the estimated coefficients (to obtain asymptotically valid standard errors under misspecifications of the $\mathrm{QR}$ function).

$$
Q_{y}(\tau \mid x)=\omega(\tau)+\sum_{k} \beta_{k}(\tau) x_{k}
$$

where $x_{k}$ represents the macroeconomic risk factors (TED, USD, DEF, TERM, and FF). The dependent variable in Equation (2) is $Q_{y}(\tau \mid x)$, which refers to the quantile of time-varying volatilities of stock portfolios derived by the EGARCH model. $\beta_{k}$ gauges the impacts of the conditional variables (TED, USD, DEF, TERM, and FF) on the volatilities of stock portfolios for all quantiles. We tested the equality of coefficients at low and high quantiles using the F-test. The findings suggest that the estimates for the lower and upper quantiles were statistically different. The results can be provided upon request.We focused our attention on high, intermediate, and low quantiles $(0.10 ; 0.25 ; 0.50 ; 0.75 ; 0.90)$. The model helped us to test whether the dependence structures between the related variables change with the value of $(\tau)$, via the effects of different conditional variables. For robustness, we also used the implied volatility of the gold, oil, currency, and stock prices from options markets (GVZ, OVX, EVZ, and VIX) to control for the impact of uncertainty in commodity and financial markets on portfolio volatilities. We did not find significant results and our main findings were not changed. The results can be provided upon request.

\section{Empirical Results and Discussion}

We used daily data of funding liquidity and other control variables and daily volatilities of stock portfolios from 2 January 2020 to 30 June 2020. The findings are presented to indicate the main determinants of the volatilities of small-growth, small-value, largegrowth, and large-value portfolios in Tables $2-5$, respectively. The results from the QR model indicate a strong right-tailed asymmetric dependence structure between funding liquidity risk and portfolio volatilities. In other words, the degrees of dependence between funding liquidity risk and portfolio volatilities increased in the higher quantiles. Consistent with our hypotheses, we observed that reduced funding liquidity (an increase in TED spread) had an adverse effect, especially on the volatilities of high-risk portfolios (increasing volatilities of portfolios), and this effect was stronger at the times of extreme volatility during the COVID-19 pandemic period. 
Table 2. Quantile regression estimates for the volatility of small-growth portfolios.

\begin{tabular}{|c|c|c|c|c|c|}
\hline \multicolumn{6}{|c|}{ Panel A. Small-Growth Equally Weighted Portfolio. } \\
\hline & $Q(0.10)$ & $Q(0.25)$ & $Q(0.50)$ & $Q(0.75)$ & $Q(0.90)$ \\
\hline TED & 0.234721 & 0.236688 & 0.721903 & $1.942046^{* * *}$ & $2.247730 * * *$ \\
\hline$\triangle \mathrm{USD}$ & 0.047474 & 0.035525 & 0.149601 & $0.295085^{* *}$ & 0.220796 \\
\hline DEF & 0.074881 & 0.306602 & -0.146603 & -1.08314 & -0.677091 \\
\hline TERM & $0.793346^{*}$ & 0.837615 & 1.247038 & $3.176875^{* *}$ & 3.907195 \\
\hline FF & 0.094832 & 0.178546 & 0.08265 & 0.118996 & 0.377945 \\
\hline Constant & -0.379109 & -0.664984 & -0.261139 & -0.046989 & -0.914749 \\
\hline Pseudo $R^{2}$ & 0.12734 & 0.129388 & 0.209409 & 0.452856 & 0.567077 \\
\hline \multicolumn{6}{|c|}{ Panel B. Small-Growth Value-Weighted Portfolio. } \\
\hline & $Q(0.10)$ & $Q(0.25)$ & $Q(0.50)$ & $Q(0.75)$ & $Q(0.90)$ \\
\hline TED & $0.184540^{* * *}$ & $0.187256^{* * *}$ & $0.293062 * * *$ & $0.373977^{* * *}$ & 0.362896 ** \\
\hline$\triangle \mathrm{USD}$ & 0.013031 & 0.022646 & $0.060762 * *$ & 0.077211 & $0.160972^{* *}$ \\
\hline $\mathrm{DEF}$ & $-0.280845^{* *}$ & $-0.293485^{* *}$ & $-0.359546^{* *}$ & -0.12897 & 0.0452 \\
\hline TERM & 0.02314 & 0.03546 & 0.138531 & 0.167228 & 0.464921 \\
\hline FF & $-0.163038^{* * *}$ & $-0.170151^{* * *}$ & $-0.198686^{* * *}$ & $-0.157414 *$ & -0.073605 \\
\hline Constant & $0.462714^{* *}$ & $0.495022 * *$ & $0.564078 * *$ & 0.300383 & -0.007143 \\
\hline Pseudo $R^{2}$ & 0.334442 & 0.388128 & 0.423552 & 0.455643 & 0.505884 \\
\hline
\end{tabular}

Notes: DEF and TERM refer to the default and term spreads, respectively. FF is the federal funds rate. TED is the difference between 3 month LIBOR based on United States (US) dollars and 3 month Treasury bill rates. $\triangle$ USD is the percentage change of the trade-weighted US dollar index. ${ }^{* * *}$ Significant at the $1 \%$ level; ${ }^{* *}$ significant at the $5 \%$ level; * significant at the $10 \%$ level. Bootstrapped standard errors can be provided upon request.

Table 3. Quantile regression estimates for the volatility of small-value portfolios.

\begin{tabular}{|c|c|c|c|c|c|}
\hline \multicolumn{6}{|c|}{ Panel A. Small-Value Equally Weighted Portfolio. } \\
\hline & $Q(0.10)$ & $Q(0.25)$ & $Q(0.50)$ & $Q(0.75)$ & $Q(0.90)$ \\
\hline TED & $0.376354^{* * *}$ & $0.317908^{* * *}$ & 0.410693 *** & $0.718187^{* * *}$ & $0.978881^{* *}$ \\
\hline$\triangle \mathrm{USD}$ & 0.000548 & 0.00373 & 0.008434 & 0.087652 & 0.313113 \\
\hline DEF & $-0.238898 *$ & -0.208575 & $-0.488392 * *$ & $-1.090692^{* * *}$ & -1.258328 \\
\hline TERM & 0.271271 & $0.558057 *$ & $0.857002 * *$ & 1.093685 & 2.0372 \\
\hline $\mathrm{FF}$ & -0.049035 & -0.05052 & -0.160062 & $-0.437519 *$ & -0.399688 \\
\hline Constant & 0.278615 & 0.224728 & 0.569798 & 1.421968 * & 1.33733 \\
\hline Pseudo $R^{2}$ & 0.217063 & 0.257554 & 0.239325 & 0.231789 & 0.270825 \\
\hline \multicolumn{6}{|c|}{ Panel B. Small-Value Value-Weighted Portfolio. } \\
\hline & $Q(0.10)$ & $Q(0.25)$ & $Q(0.50)$ & $Q(0.75)$ & $Q(0.90)$ \\
\hline TED & -0.000752 & -0.000743 & 0.0000585 & -0.008194 & -0.002665 \\
\hline$\triangle \mathrm{USD}$ & -0.00000262 & 0.000287 & -0.001054 & 0.005543 & 0.008296 \\
\hline DEF & 0.001029 & 0.001119 & 0.001099 & 0.020052 & 0.059845 \\
\hline TERM & 0.000602 & 0.000329 & 0.006501 & 0.065065 * & 0.129994 \\
\hline FF & 0.000716 & 0.000724 & 0.000637 & 0.011039 & 0.029894 \\
\hline Constant & 0.008017 * & $0.008519 * *$ & 0.007949 & -0.030327 & -0.103881 \\
\hline Pseudo $R^{2}$ & 0.010066 & 0.008512 & 0.010173 & 0.057574 & 0.136328 \\
\hline
\end{tabular}

Notes: DEF and TERM refer to the default and term spreads, respectively. FF is the federal funds rate. TED is the difference between 3 month LIBOR based on United States (US) dollars and 3 month Treasury bill rates. $\triangle$ USD is the percentage change of the trade-weighted US dollar index. ${ }^{* * *}$ Significant at the $1 \%$ level; ${ }^{* *}$ significant at the $5 \%$ level; * significant at the $10 \%$ level. Bootstrapped standard errors can be provided upon request. 
Table 4. Quantile regression estimates for the volatility of large-growth portfolios.

\begin{tabular}{|c|c|c|c|c|c|}
\hline \multicolumn{6}{|c|}{ Panel A. Large-Growth Equally Weighted Portfolio. } \\
\hline & $Q(0.10)$ & $Q(0.25)$ & $Q(0.50)$ & $Q(0.75)$ & $Q(0.90)$ \\
\hline TED & $0.057825^{* *}$ & $0.059409 * * *$ & $0.085593^{* * *}$ & 0.116622 ** & $0.263153^{* * *}$ \\
\hline$\triangle \mathrm{USD}$ & $0.020687^{* *}$ & $0.014007^{* *}$ & 0.005258 & -0.00285 & -0.025197 \\
\hline DEF & 0.04513 & 0.049136 & 0.107896 ** & 0.120761 * & -0.051614 \\
\hline TERM & 0.030569 & -0.016687 & 0.122692 & 0.211246 * & 0.11847 \\
\hline FF & -0.039047 & -0.036754 & 0.016993 & 0.03922 & -0.023951 \\
\hline Constant & 0.00464 & 0.030539 & -0.114772 & -0.158364 & 0.097188 \\
\hline Pseudo $R^{2}$ & 0.479252 & 0.498959 & 0.451702 & 0.511832 & 0.591971 \\
\hline \multicolumn{6}{|c|}{ Panel B. Large-Growth Value-Weighted Portfolio. } \\
\hline & $Q(0.10)$ & $Q(0.25)$ & $Q(0.50)$ & $Q(0.75)$ & $Q(0.90)$ \\
\hline TED & -0.001756 & 0.003299 & 0.011282 & $0.024566^{* * *}$ & $0.030680^{* * *}$ \\
\hline$\triangle \mathrm{USD}$ & 0.003354 & 0.002095 & 0.002067 & $0.005567 *$ & 0.000559 \\
\hline DEF & -0.003612 & -0.006916 & -0.024166 & $-0.035958^{* *}$ & -0.036660 * \\
\hline TERM & -0.024407 & -0.01805 & -0.020038 & -0.004958 & 0.0113 \\
\hline FF & -0.00972 & -0.010383 * & $-0.015627^{* *}$ & $-0.017006^{*}$ & -0.016994 \\
\hline Constant & 0.031545 & 0.034851 * & $0.060843 * * *$ & $0.070789 * *$ & $0.071852^{* *}$ \\
\hline Pseudo $R^{2}$ & 0.231057 & 0.200836 & 0.155465 & 0.264051 & 0.40097 \\
\hline
\end{tabular}

Notes: DEF and TERM refer to the default and term spreads, respectively. FF is the federal funds rate. TED is the difference between 3 month LIBOR based on United States (US) dollars and 3 month Treasury bill rates. $\triangle$ USD is the percentage change of the trade-weighted US dollar index. ${ }^{* * *}$ Significant at the $1 \%$ level; ${ }^{* *}$ significant at the $5 \%$ level; * significant at the $10 \%$ level. Bootstrapped standard errors can be provided upon request.

Table 5. Quantile regression estimates for the volatility of large-value portfolios.

\begin{tabular}{cccccc}
\hline \multicolumn{6}{c}{ Panel A. Large-Value Equally Weighted Portfolio. } \\
\hline Q(0.10) & $\mathbf{Q ( 0 . 2 5 )}$ & $\mathbf{Q ( 0 . 5 0 )}$ & $\mathbf{Q ( 0 . 7 5 )}$ & $\mathbf{Q ( 0 . 9 0 )}$ \\
\hline TED & $0.167429 *$ & 0.254026 & 0.727135 & $1.899838^{* *}$ & $3.267949^{* * *}$ \\
$\triangle$ USD & -0.029857 & 0.007557 & 0.030555 & 0.341193 & $0.775099^{* *}$ \\
DEF & -0.155227 & -0.234264 & -0.437051 & -1.751534 & $-3.526708^{* * *}$ \\
TERM & 0.118714 & 0.124401 & 0.004214 & 2.109121 & $6.369875^{*}$ \\
FF & $-0.089173 *$ & -0.122854 & -0.237384 & -0.363936 & -0.384064 \\
Constant & 0.235083 & 0.348287 & 0.628144 & 1.396381 & 1.943676 \\
Pseudo $R^{2}$ & 0.135034 & 0.145326 & 0.171951 & 0.29532 & 0.51744 \\
\hline \multicolumn{7}{c}{ Panel B. Large-Value Value-Weighted Portfolio. } & \\
\hline TED & $\mathbf{Q ( 0 . 1 0 )}$ & $\mathbf{Q ( 0 . 2 5 )}$ & $\mathbf{Q}(\mathbf{0 . 5 0 )}$ & $\mathbf{Q ( 0 . 7 5 )}$ & $\mathbf{Q ( 0 . 9 0 )}$ \\
\hline USD & 0.01937 & 0.034151 & $0.102227 * *$ & 0.120011 & $0.201852 *$ \\
DEF & 0.00563 & 0.005978 & 0.030819 & $0.107029 * *$ & $0.180916^{* *}$ \\
TERM & -0.013253 & -0.02057 & -0.095394 & -0.059272 & -0.247992 \\
FF & 0.014616 & $0.172264 * *$ & 0.235401 & $0.667151 *$ & $1.105126^{* *}$ \\
Constant & -0.008836 & 0.011705 & -0.011096 & 0.038622 & -0.017313 \\
Pseudo $R^{2}$ & 0.083138 & 0.029942 & 0.113101 & -0.063273 & 0.102046 \\
\hline
\end{tabular}

Notes: DEF and TERM refer to the default and term spreads, respectively. FF is the federal funds rate. TED is the difference between 3 month LIBOR based on United States (US) dollars and 3 month Treasury bill rates. $\triangle$ USD is the percentage change of the trade-weighted US dollar index. ${ }^{* * *}$ Significant at the $1 \%$ level; ${ }^{* *}$ significant at the $5 \%$ level; * significant at the $10 \%$ level. Bootstrapped standard errors can be provided upon request.

The strong asymmetric association between funding liquidity risk and high-risk portfolio volatilities appeared to be due to the COVID-19 crisis having a large effect on uncertainty perceptions of financial intermediaries. The adverse impacts of deteriorated funding liquidity conditions on the volatilities of stock portfolios during high-volatility episodes were stronger because perceived equity risk was high in these episodes. Financial intermediaries (such as speculators in financial markets) appeared to be more attentive to the volatilities of high-risk portfolios in the high-volatility periods. It was apparent that the 
increased risk aversion of financial intermediaries coincided with the high-volatility periods of more risky portfolios, which was the main reason behind the asymmetric dependence. The intermediaries tended to reevaluate the downside risks of their investment strategies considering the level of portfolio volatilities during the economic slowdown in the COVID19 crisis period.

As for the impact of other control variables, we observed that an increase in the value of the US dollar ( $\triangle \mathrm{USD}$ ) significantly increased the volatilities of some portfolios, particularly for the high periods of high-risk portfolio volatilities. This could be due to the fact that the US dollar is a valuable hedge against worsening economic conditions, and significant US dollar appreciations represent one of the indicators of these conditions [35]. Similar to the impact of the US dollar, it was observed that an increase in TERM spread (TERM) intensified the volatility of high-risk portfolios, especially in the upward periods of the volatilities. The main reason behind this result is that the TERM spread is associated with short-term business cycles and is expected to be high in tough times [33]. Another interesting finding is that reduced interest rates (the decreases in FF) led to increasing volatilities for some portfolios (with more increase for small-growth value-weighted and small-value equally weighted portfolios). During recessions, interest rate cuts by monetary authorities can lead to expectations for further cuts [42]. This could be the probable reason for the impact of interest rate cuts during the COVID-19 crisis. Last but not least, we also found that the increased default spread reduced the volatility of some portfolios (e.g., small-growth value-weighted, small-value equally weighted, large-growth value-weighted, and large-value equally weighted portfolios), while it increased the volatility of the largegrowth equally weighted portfolio. The differential impacts of default spread suggest that the widely used default spreads (e.g., the default spread used in this study) could not be related to the real default risk since individual companies in different portfolios have different and time-varying default probabilities [43].

\section{Conclusions}

During periods of extreme uncertainty (such as the uncertain COVID-19 pandemic period), a better understanding of economic mechanisms affecting the volatilities of stock portfolios is of immense importance for determining effective investment strategies. The limited risk-bearing capacity of financial intermediaries, which depends on the changes in funding liquidity conditions in interbank markets, affects global market dynamics [9]. The behavior of financial intermediaries (speculators in financial markets), buying and/or selling volatile stocks, influences the demand-supply mechanism in stock markets due to the large holdings they have at their disposal. This behavior varies with changing global economic circumstances. Risky portfolios can be immediately affected by market news in an uncertain economic environment, which leads to risk-adjusting changes in the asset allocation decisions of financial intermediaries. In this paper, we analyzed the asymmetric dependence structure between funding liquidity risk and the volatilities of lowand high-risk stock portfolios during the COVID-19 period. Specifically, we tested whether the significance and magnitude of the effects of funding liquidity risk on the volatilities of stock portfolios changed during the high-volatility periods with high uncertainty that coincided with the COVID-19 period.

Our baseline results indicate two important findings. First, the deteriorated funding liquidity conditions had serious adverse effects on the volatilities of high-risk portfolios (increasing volatilities of high-risk portfolios) compared to low-risk portfolios during the COVID-19 pandemic. Second and more importantly, these effects were more significant and stronger in the upward periods of the volatilities of high-risk portfolios, which inherently have more information risk. The findings imply that the volatilities of high-risk portfolios were strongly associated with worsening funding liquidity conditions in interbank markets, especially during the panic periods of the COVID-19 crisis. It appears that a decline in the risk-bearing capacity of financial intermediaries increased the volatilities of high-risk portfolios more strongly when financial intermediaries related an increase in volatility 
to worsening investment opportunities in global markets. This economic mechanism especiall reduces the diversification capacity of, the high-risk portfolio investments in high-uncertainty environments. To sum up, our main findings provide valuable insights to asset managers into how funding liquidity risk drives the volatility of stock portfolios in an uncertain economic environment. Baseline results suggest the use of dynamic asset allocation strategies to reduce volatility exposure against funding liquidity risk during uncertain times. Tactical asset allocation strategies can be used to successfully manage significant fluctuations in the volatility of stock portfolios. Employing a tactical asset allocation strategy, the global asset managers might form their asset allocation decisions to change their position in stock markets depending on portfolio volatility levels and on the changes in funding liquidity risk.

Our results imply that increased financial constraints of financial intermediaries are causing market inefficiency due to increased financial frictions (e.g., informational loss, information asymmetry) during the turbulent and uncertain COVID-19 pandemic. The uncertain pandemic crisis increases information risk, as well as liquidity risk and, hence, transaction costs, which are considered as speculators' shadow cost of capital [9], leading to more illiquid stock markets and higher hedging motives. As a result of this mechanism, illiquid and highly volatile stocks are especially strongly influenced by a negative shock to interbank loan markets in high volatility periods. Overall, we provide evidence on the role of hedging demands in determining the asymmetric impacts of the reduced risk-bearing capacity of financial intermediaries on portfolio volatilities through uncertainty during the COVID-19 pandemic crisis. Following a negative shock to the global economy, larger losses are observed because of the high-risk positions of US financial intermediaries, since they tend to make risky investments in good times [35]. The precautionary measures taken by financial intermediaries (e.g., safer US dollar liabilities) in good times might increase their resilience to negative global economic conditions [35] and lessen the adverse impacts of funding liquidity risk on the volatilities of high-risk portfolios in bad times (e.g., the COVID-19 related financial turmoil).

As an extension to this study, rather than size and value strategies, the volatility of portfolios formed based on other investment strategies (e.g., size and profitability strategies) may be further studied. Future research may also concentrate on the role of the equity constraints of financial intermediaries in determining the volatilities of stock portfolios instead of the debt constraints examined in this study. For additional extensions, the effects of positive and negative changes in funding liquidity risk on other asset markets could be tested. For example, a future study might investigate the effects of positive and negative changes in funding liquidity risk on the volatility of portfolios, including assets with different risk profiles in developed and/or developing markets. Such a study may yield important insights for asset managers and policymakers.

Author Contributions: All authors contributed equally to this work. All authors have read and agreed to the published version of the manuscript.

Funding: This research received no external funding.

Institutional Review Board Statement: Not applicable.

Informed Consent Statement: Not applicable.

Data Availability Statement: Publicly available datasets were analyzed in this study. Portfolio returns can be found in Kenenth French's online data library: [https:/ / mba.tuck.dartmouth.edu/ pages/faculty/ken.french/data_library.html] (accessed on 7 February 2021). Other variables are sourced from Federal reserve Bank of St. Louis: [https://www.stlouisfed.org/] (accessed on 7 February 2021).

Acknowledgments: This paper is a revised version of a part of the first author's PhD dissertation submitted to the Middle East Technical University, Ankara.

Conflicts of Interest: The authors declare no conflict of interest. 


\section{References}

1. Goodell, J.W. COVID-19 and finance: Agendas for future research. Financ. Res. Lett. 2020, 35, 101512. [CrossRef]

2. Sharif, A.; Aloui, C.; Yarovaya, L. COVID-19 pandemic, oil prices, stock market, geopolitical risk and policy uncertainty nexus in the US economy: Fresh evidence from the wavelet-based approach. Int. Rev. Financ. Anal. 2020, 70, 101496. [CrossRef]

3. Choi, S.Y. Industry volatility and economic uncertainty due to the COVID-19 pandemic: Evidence from wavelet coherence analysis. Financ. Res. Lett. 2020, 37, 101783. [CrossRef]

4. Albulescu, C.T. COVID-19 and the United States financial markets' volatility. Financ. Res. Lett. 2021, 38, 101699. [CrossRef] [PubMed]

5. Zhang, D.; Hu, M.; Ji, Q. Financial markets under the global pandemic of COVID-19. Financ. Res. Lett. 2020, 36, 101528. [CrossRef]

6. Mazur, M.; Dang, M.; Vega, M. COVID-19 and the march 2020 stock market crash. Evidence from S\&P1500. Financ. Res. Lett. 2020, 38, 101690. [PubMed]

7. Engelhardt, N.; Krause, M.; Neukirchen, D.; Posch, P.N. Trust and stock market volatility during the COVID-19 crisis. Financ. Res. Lett. 2020, 38, 101873. [CrossRef]

8. Engelhardt, N.; Krause, M.; Neukirchen, D.; Posch, P. What drives stocks during the corona-crash? News attention vs. rational expectation. Sustainability 2020, 12, 5014. [CrossRef]

9. Brunnermeier, M.K.; Pedersen, L.H. Market liquidity and funding liquidity. Rev. Financ. Stud. 2009, 22, 2201-2238. [CrossRef]

10. Moreira, A.; Savov, A. The macroeconomics of shadow banking. J. Financ. 2017, 72, 2381-2432. [CrossRef]

11. Bekaert, G.; Engstrom, E.; Xing, Y. Risk, uncertainty, and asset prices. J. Financ. Econ. 2009, 91, 59-82. [CrossRef]

12. Bloom, N. Fluctuations in uncertainty. J. Econ. Perspect. 2014, 28, 153-176. [CrossRef]

13. He, Z.; Kelly, B.; Manela, A. Intermediary asset pricing: New evidence from many asset classes. J. Financ. Econ. 2017, 126, 1-35. [CrossRef]

14. Bae, K.H.; Karolyi, G.A.; Stulz, R.M. A new approach to measuring financial contagion. Rev. Financ. Stud. 2003, 16, 717-763. [CrossRef]

15. Karpoff, J.M. The relation between price changes and trading volume: A survey. J. Financ. Quant. Anal. 1987, 22, 109-126. [CrossRef]

16. Lamoureux, C.G.; Lastrapes, W.D. Heteroskedasticity in stock return data: Volume versus GARCH effects. J. Financ. 1990, 45, 221-229. [CrossRef]

17. Schwert, G.W. Why does stock market volatility change over time? J. Financ. 1989, 44, 1115-1153. [CrossRef]

18. Amihud, Y.; Mendelson, H. Asset pricing and the bid-ask spread. J. Financ. Econ. 1986, 17, 223-249. [CrossRef]

19. Constantinides, G.M. Capital market equilibrium with transaction costs. J. Polit. Econ. 1986, 94, 842-862. [CrossRef]

20. Heaton, J.; Lucas, D.J. Evaluating the effects of incomplete markets on risk sharing and asset pricing. J. Polit. Econ. 1996, 104, 443-487. [CrossRef]

21. Huang, M. Liquidity shocks and equilibrium liquidity premia. J. Econ. Theory 2003, 109, 104-129. [CrossRef]

22. Bali, T.G.; Cakici, N.; Yan, X.S.; Zhang, Z. Does idiosyncratic risk really matter? J. Financ. 2005, 60, 905-929. [CrossRef]

23. Cao, H.H.; Wang, T.; Zhang, H.H. Model uncertainty, limited market participation, and asset prices. Rev. Financ. Stud. 2005, 18, 1219-1251. [CrossRef]

24. Mele, A. Asymmetric stock market volatility and the cyclical behavior of expected returns. J. Financ. Econ. 2007, 86, 446-478. [CrossRef]

25. Goodell, J.W.; Goutte, S. Co-movement of COVID-19 and Bitcoin: Evidence from wavelet coherence analysis. Financ. Res. Lett. 2020, 38, 101625. [CrossRef]

26. Erdem, O. Freedom and stock market performance during Covid-19 outbreak. Financ. Res. Lett. 2020. [CrossRef] [PubMed]

27. Nelson, D.B. Conditional heteroskedasticity in asset returns: A new approach. Econom. J. Econom. Soc. 1991, 59, 347-370. [CrossRef]

28. Fu, F. Idiosyncratic risk and the cross-section of expected stock returns. J. Financ. Econ. 2009, 91, 24-37. [CrossRef]

29. Engle, R.F.; Ng, V.K. Measuring and testing the impact of news on volatility. J. Financ. 1993, 48, 1749-1778. [CrossRef]

30. Fama, E.F.; French, K.R. Common risk factors in the returns on stocks and bonds. J. Financ. Econ. 1993, 33, 3-56. [CrossRef]

31. Carhart, M.M. On persistence in mutual fund performance. J. Financ. 1997, 52, 57-82. [CrossRef]

32. Fama, E.F.; French, K.R. International tests of a five-factor asset pricing model. J. Financ. Econ. 2017, 123, 441-463. [CrossRef]

33. Fama, E.F.; French, K.R. Business conditions and expected returns on stocks and bonds. J. Financ. Econ. 1989, 25, 23. [CrossRef]

34. Hamilton, J.D.; Jorda, O. A model of the federal funds rate target. J. Polit. Econ. 2002, 110, 1135-1167. [CrossRef]

35. Maggiori, M. Financial intermediation, international risk sharing, and reserve currencies. Am. Econ. Rev. 2017, 107, 3038-3071. [CrossRef]

36. Spindt, P.A.; Hoffmeister, J.R. The micromechanics of the federal funds market: Implications for day-of-the-week effects in funds rate variability. J. Financ. Quant. Anal. 1988, 23, 401-416. [CrossRef]

37. Koenker, R.; Bassett, G., Jr. Regression quantiles. Econom. J. Econom. Soc. 1978, 46, 33-50. [CrossRef]

38. Fousekis, P.; Tzaferi, D. Price returns and trading volume changes in agricultural futures markets: An empirical analysis with quantile regressions. J. Econ. Asymmetries 2019, 19, e00116. [CrossRef]

39. Xue, W.; Zhang, L. Revisiting the asymmetric effects of bank credit on the business cycle: A panel quantile regression approach. J. Econ. Asymmetries 2019, 20, e00122. [CrossRef] 
40. Koenker, R.; Hallock, K.F. Quantile regression. J. Econ. Perspect. 2001, 15, 143-156. [CrossRef]

41. Buchinsky, M. Estimating the asymptotic covariance matrix for quantile regression models a Monte Carlo study. J. Econom. 1995, 68, 303-338. [CrossRef]

42. Caplin, A.; Leahy, J. Monetary policy as a process of search. Am. Econ. Rev. 1996, 86, 689-702.

43. Vassalou, M.; Xing, Y. Default risk in equity returns. J. Financ. 2004, 59, 831-868. [CrossRef] 